\title{
CD147 expression correlates with lymph node metastasis in T1-T2 squamous cell carcinoma of the tongue
}

\author{
SHINSUKE SUZUKI $^{1}$, KOHEI HONDA ${ }^{1}$, HIROSHI NANJO ${ }^{2}$, NOBUKO IIKAWA ${ }^{1}$, TADAHIRO TSUJI ${ }^{1}$, \\ YOHEI KAWASAKI ${ }^{1}$, KAZUHARU YAMAZAKI $^{1}$, TERUYUKI SATO ${ }^{1}$, HIDEKAZU SAITO ${ }^{1}$, \\ KAZUHIRO SHIINA ${ }^{1}$ and KAZUO ISHIKAWA ${ }^{1}$ \\ ${ }^{1}$ Department of Otorhinolaryngology and Head and Neck Surgery, Akita University Graduate School of Medicine; \\ ${ }^{2}$ Division of Surgical Pathology, Akita University Hospital, Akita 010-8543, Japan
}

Received April 25, 2016; Accepted March 3, 2017

DOI: $10.3892 / 01.2017 .6808$

\begin{abstract}
Cervical lymph node metastasis causes a poor prognosis in cases of stage T1-T2 squamous cell carcinoma (SCC) of the tongue. Recent studies have reported that cluster of differentiation (CD)147, also known as extracellular matrix metalloproteinase inducer, contributes to tumor progression. The present study evaluated the role of CD147 in the tumorigenesis of SCC of the tongue in vitro, as well as the association between CD147 expression and cervical lymph node metastasis in clinical samples of SCC of the tongue. Tongue SCC cell lines were used to evaluate in vitro tumorigenesis. In addition, 41 patients with clinical stage T1-T2 tongue SCC were assessed with a histopathological analysis. Univariate and multivariate analysis were performed to investigate the risk of cervical lymph node metastasis associated with histopathological findings. In the in vitro study, cell invasiveness was upregulated by S100 calcium-binding protein A9 (S100A9) stimulation and downregulated following CD147-blocking antibody treatment. The univariate and multivariate analyses identified CD147 expression in the invasive tumor front as an independent risk factor for metastasis. It was concluded that CD147 induces tongue carcinoma cell invasion through its interaction with S100A9. Thus, an evaluation of the extent of CD147 expression in cancer cell nests at the invasive tumor front may help in predicting cervical lymph node metastasis in patients with clinical N0 T1-T2 tongue SCC.
\end{abstract}

\section{Introduction}

Clinically, cervical lymph node metastases causes a negative prognosis in patients with head and neck squamous cell

Correspondence to: Dr Shinsuke Suzuki, Department of Otorhinolaryngology and Head and Neck Surgery, Akita University Graduate School of Medicine, 1-1-1 Hondo, Akita 010-8543, Japan E-mail: suzukis@med.akita-u.ac.jp

Key words: cervical lymph node, S100A9, MMP, head and neck cancer carcinoma (HNSCC), particularly those with stage T1-T2 SCC of the tongue (1). However, cervical lymph node metastases are difficult to detect, and the determination of which cases should undergo neck dissection surgery remains controversial $(2,3)$. Various methods to predict cervical lymph node metastasis have been proposed in an attempt to improve the prognosis of patients with T1-T2 SCC of the tongue, including the use of predictive clinical factors such as tumor size or invasion depth, and pathological factors such as differentiation phenotype and vascular invasion (4). Previous studies have also reported correlations between the expression levels of specific proteins and lymph node metastases $(5,6)$. Therefore, lymph node metastasis prediction has been examined from a number of angles.

According to several previous studies, cluster of differentiation (CD)147, also known as extracellular matrix metalloproteinase (MMP) inducer, is overexpressed in cancer cells, and induces malignant characteristics in various types of tumor, including HNSCC $(7,8)$. Notably, CD147 expression has been associated with lymph node metastasis in HNSCC (9). However, the role of CD147 in the progression of tumors, including HNSCC, is not completely understood yet, and the detailed role of CD147 in lymph node metastasis has not been evaluated in the context of T1-T2 SCC of the tongue. Accordingly, detailed basic and clinical studies of CD147 are required to improve the prognosis of patients with HNSCC.

A large number of studies have attempted to reveal the mechanisms underlying CD147-induced tumorigenicity $(10,11)$. In our previous study, it was reported that CD147 increased HNSCC cell invasiveness, proliferation and drug resistance through interactions with its ligand, cyclophilin A (12). Thus, further analysis of CD147 and its ligands is important.

S100 calcium-binding protein A9 (S100A9) belongs to the calcium-binding protein family, which comprises 21 subfamilies, each of which has various functions that are associated with inflammation or tumor progression $(13,14)$. Previous reports have indicated that S100A9 is overexpressed and contributes to cancer progression in several types of solid tumor (14). Notably, S100A9 was previously reported to be a specific ligand of CD147 (11). However, the role of S100A9-CD147 interaction in HNSCC has not been elucidated to date. In the present study, the association of CD147 expression with cervical lymph node metastasis in T1-T2 SCC of the tongue was evaluated 
retrospectively. In addition, the role of the S100A9-CD147 interaction in SCC of the tongue was assessed.

\section{Materials and methods}

Cell lines and cell culture. SAS and HSC-3 cell lines, which are derived from human SCC of the tongue and express CD147 (15,16), were obtained from the Japanese Collection of Research Bioresources Cell Bank (Osaka, Japan). FaDu cells, a human hypopharyngeal SCC cell line that expresses CD147 (17), were a kind gift from the Department of Cell Biology and Morphology, Akita University Graduate School of Medicine (Akita, Japan). Cells were maintained in Dulbecco's modified Eagle's medium (DMEM; Sigma-Aldrich; Merck KGaA, Darmstadt, Germany) supplemented with $10 \%$ heat-inactivated fetal bovine serum (FBS; Sigma-Aldrich; Merck KGaA) and incubated at $37^{\circ} \mathrm{C}$ in the presence of $5 \% \mathrm{CO}_{2}$.

Western blotting. SAS, HSC-3 and FaDu cell lines were lysed in detergent containing $1 \%$ NP-40, $0.1 \mathrm{mM}$ phenylmethylsulfonyl fluoride, $1 \mathrm{mg} / \mathrm{ml}$ leupeptin and $1 \mathrm{mg} / \mathrm{ml}$ aprotinin, and protein levels were determined using the Bio-Rad protein assay method (Bio-Rad Laboratories, Inc., Hercules, CA, USA). Total protein $(40 \mu \mathrm{g})$ was separated on $8 \%$ SDS-PAGE gels and transferred to nitrocellulose membranes using the semi-dry transfer machine (Bio-Rad Laboratories, Inc.). Membranes were blocked with 5\% skimmed milk/TBS with Tween-20 (TBS-T) solution for $2 \mathrm{~h}$ at room temperature, and incubated with primary antibodies including against $\beta$-actin (dilution 1:1,000, cat. no. ab8227; Abcam, Cambridge, UK) and CD147 (rabbit anti-human polyclonal, dilution 1:1,000, cat. no. sc-13976; Santa Cruz Biotechnology, Inc.), in 5\% skimmed milk/TBS-T overnight at $4^{\circ} \mathrm{C}$. Subsequent to washing with TBS-T three times, membranes were incubated for $1 \mathrm{~h}$ at room temperature with a goat anti-rabbit horseradish peroxidase-conjugated secondary antibody (dilution 1:3,000, cat. no. 170-6515; Bio-Rad Laboratories, Inc.). The filters were rinsed with TBS-T three times, and the blot was developed using Luminol reagent (Santa Cruz Biotechnology Inc., Dallas, TX, USA) by autoradiography.

Matrigel invasion assay. Cell invasiveness was evaluated in vitro using Matrigel-coated semipermeable modified Boyden inserts with a pore size of $8 \mu \mathrm{m}$ (BD Biosciences, Franklin Lakes, NJ, USA). SAS and HSC-3 cells were plated at a density of $2.5 \times 10^{4}$ cells per insert in serum-free medium with S100A9 (100 nM; ATGen Co., Ltd., Gyeonggi, South Korea), anti-CD147 function-blocking antibody (10 $\mu \mathrm{g} / \mathrm{ml}$, UM-8D6, cat. no. 10R-CD147aHU; Research Diagnostics, Inc., Flanders, NJ, USA), for which the blocking activity has been previously described $(18,19)$, a negative control mouse $\operatorname{IgG}(10 \mu \mathrm{g} / \mathrm{ml}$, cat. no. X0931; Santa Clara, CA, USA) or a combination of S100A9 with anti-CD147 or control IgG. The lower chamber contained DMEM with $10 \%$ FBS as a chemoattractant. To control for the effect of inhibitors on cell growth, the cells were also plated in parallel in a 96-well plate with identical conditions. After $48 \mathrm{~h}$ of treatment at $37^{\circ} \mathrm{C}$ in a $5 \% \mathrm{CO}_{2}$ incubator, the cells on the upper side of the insert were removed by wiping gently with a cotton swab. Cells on the reverse side of the insert were fixed and stained using Differential Quik Stain kit (Sysmex
Corporation, Kobe, Japan) according to the manufacturer's instructions. Invading cells in four representative fields were manually counted using light microscopy at x200 magnification. The mean \pm standard deviation was calculated from three independent experiments. Cells in the 96-well plate were further assessed via an MTT assay to identify the relative quantity of viable cells. Produced formazan was dissolved in dimethyl sulfoxide and the concentration was determined by optical density at $570 \mathrm{~nm}$. The numbers of invading cells were adjusted accordingly. MTT and DMSO were purchased from Nacalai Tesque, Inc. (Kyoto, Japan).

Patients. A total of 41 patients (including 25 male and 16 female patients) with previously untreated, clinically diagnosed stage I and II (T1 and T2 without lymph node metastasis, respectively) SCC of the tongue and pathologically confirmed subepithelial invasion, who underwent surgery between April 2007 and November 2012 at the Department of Otolaryngology, Akita University Hospital (Akita, Japan), were retrospectively enrolled in the present study. The tumors were classified according to the 2002 Union for International Cancer Control staging system (20). All patients presented with T1 or T2 primary lesions at the clinical or radiological stage N0 (T1N0, 12 patients; T2N0, 20 patients). The patients ranged in age from 33 to 83 years (median, 65.8 years; Table I). Patients were followed up for $>12$ months after surgery.

Patients with clinically diagnosed T1/T2 N0 SCC of the tongue underwent sentinel lymph node (SLN) biopsy, and those with positive SLNs underwent neck dissection. In the present study, patients whose lymph node metastases were detected by SLN biopsy and those whose lymph node metastases were detected during the follow-up period were classified into the lymph node metastasis-positive group.

Immunohistochemistry and classification of pathological findings. Excised primary tumor specimens were fixed with $10 \%$ neutral buffered formalin, and consecutive sections were cut every $5 \mathrm{~mm}$ and $4-\mu \mathrm{m}$ thick tissue sections were obtained. The sections were stained with hematoxylin and eosin, and the section containing the invasive tumor front was selected for further analysis. The previously described polyclonal anti-CD147 antibody was used as the primary antibody for immunohistochemical staining. In brief, $4-\mu \mathrm{m}$-thick sections were deparaffinized and were initially autoclaved for $15 \mathrm{~min}$ at $121^{\circ} \mathrm{C}$. Sections were then were blocked with $0.3 \%$ hydrogen peroxide in methanol for $30 \mathrm{~min}$ at room temperature and with $10 \%$ normal rabbit serum/Tris (Vector Laboratories, Inc., Burlingame, CA, USA) for $30 \mathrm{~min}$ at room temperature. All sections were kept overnight at $4^{\circ} \mathrm{C}$ in phosphate-buffered saline (PBS) containing the rabbit anti-human CD147 polyclonal antibody (dilution 1:200), followed by a $1 \mathrm{~h}$ incubation with biotinylated anti-rabbit IgG (ready-to-use dilution, cat. no. ab64256; Abcam) at room temperature. The sections were washed with PBS, and protein expression was detected with the Vectastain avidin-biotin complex kit (Vector Laboratories, Inc.) according to the manufacturer's instructions, and then reacted with diaminobenzidine (Nacalai Tesque, Inc.) for 3 to $5 \mathrm{~min}$ at room temperature.

A pathologist and a surgeon evaluated the CD147 immunohistochemical staining. CD147 expression in a cancer cell nest at the invasive tumor front was identified and scored according 
A

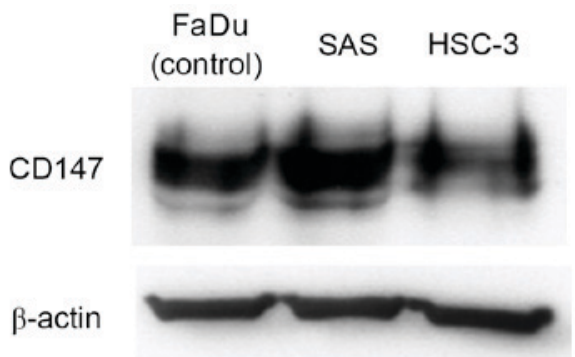

B

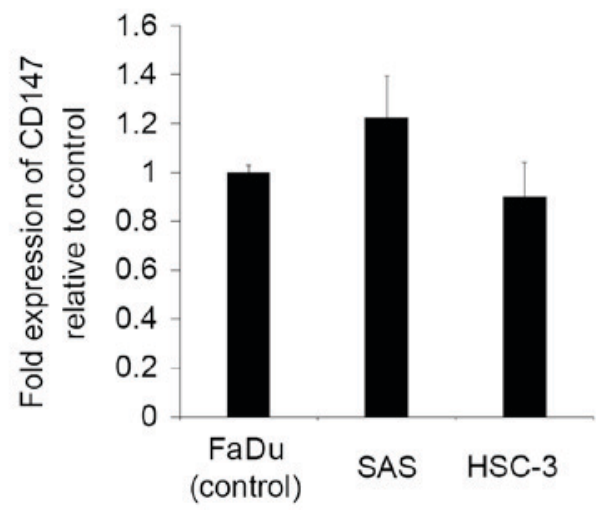

Figure 1. The tongue SCC cell lines SAS and HSC-3 express CD147. CD147 protein expression was detected by a western blotting of the tongue SCC cell lines SAS and HSC-3. CD147-positive FaDu cells were used as a positive control. (A) Representative western blotting of CD147 levels in the aforementioned cells. (B) Densitometry analysis was performed on the blots of CD147 expression levels relative to CD147 expression in FaDu cells. Data are expressed as the mean \pm standard deviation from three repetitions. SCC, squamous cell carcinoma; CD147, cluster of differentiation 147.

to the staining strength and intensity at x200 magnification under light microscopy. Areas of CD147 staining received a score of 0 if $<10 \%$ of cells of the tumor nest were stained, a score of 1 if $\geq 10 \%$ but $<50 \%$ of cells of the tumor nest were stained, and a score of 2 if $\geq 50 \%$ of cells of the tumor nest were stained. The CD147 staining intensity was also scored from 0 to 2 (negative, weak or strong staining, which we scored as 0-2, respectively), and a CD147 index (range, 0-4) was calculated, as CD147-positive area score (0-2) x CD147 intensity score (0-2). An index of 4 was classified as positive upon setting the cut-off value at 3.5 , which was the mean value of the CD147 index.

In addition, hematoxylin and eosin-stained samples were examined to determine the SCC differentiation type, the presence or absence of lymphovascular, vascular and perineural invasion, and the depth of invasion. Samples were classified according to the pathological findings as poorly, moderately or well differentiated, and assessed for the presence or absence of lymphovascular, vascular and/or perineural invasion. The invasion depth was classified as $\geq 5$ or $<5 \mathrm{~mm}$, according to a previous study on increased cervical lymph node metastasis at invasion depths exceeding 4-5 $\mathrm{mm}$ (20).

Statistical analysis. Statistical analyses were performed using JMP 11 software (SAS Institute, Inc., Cary, NC, USA). A two-tailed Mann-Whitney U test was used to assess the statistical significance of differences in the invasion studies.
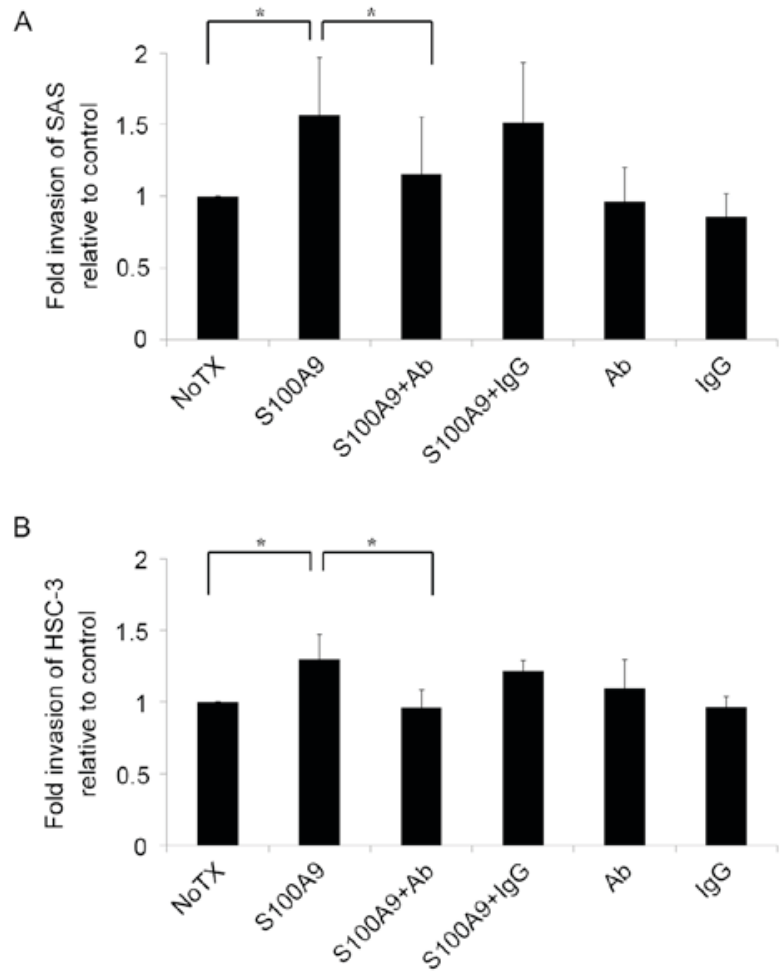

Figure 2. S100A9 induces tongue SCC cell invasion through its interaction with CD147. Cell invasiveness was evaluated in vitro using a Matrigel invasion assay. (A) SAS and (B) HSC-3 tongue SCC cells were plated in the inserts in serum-free medium with or without S100A9 $(100 \mathrm{nM}), \mathrm{Ab}(10 \mu \mathrm{g} / \mathrm{ml}), \mathrm{IgG}$ $(10 \mu \mathrm{g} / \mathrm{ml})$ or a combination of S100A9 with Ab or S100A9 with IgG. Untreated cells were used as a control. The results are shown as fold-changes in invasion relative to the control. Both (A) SAS and (B) HSC-3 cell invasiveness increased in response to S100A9 stimulation, and the addition of $\mathrm{Ab}$ reversed this increase. The experiment was repeated three times, and fold invasiveness relative to control was expressed as the mean \pm standard deviation. ${ }^{*} \mathrm{P}<0.05$ compared with the NoTX group. S100A9, S100 calcium-binding protein A9; SCC, squamous cell carcinoma; CD147, cluster of differentiation 147; Ab, antibody; IgG, immunoglobulin G; NoTX, no treatment.

Univariate and multivariate analyses were performed using a logistic regression model to evaluate risk factors for metastasis. $\mathrm{P}<0.05$ was considered to indicate a statistically significant difference.

\section{Results}

SAS and HSC-3 cells express CD147. Prior to evaluating the role of CD147 in the tongue SCC cell lines SAS and HSC-3, its relative protein expression was determined by western blotting. $\mathrm{FaDu}$, a human hypopharyngeal $\mathrm{SCC}$ cell line reported to express CD147, was used as a positive control. SAS and HSC-3 cells were observed to express CD147 at a high level (Fig. 1), indicating that they were suitable for use in further studies.

S100A9 induces tongue SCC cell invasion through its interaction with CD147. As tumor cell invasion is an important stage in the metastasis cascade, there is a focus on invasion control as a target for clinical tumor suppression $(21,22)$. To improve the understanding of the mechanisms underlying tongue SCC cell invasion, SAS and HSC-3 cells were seeded into Matrigel invasion chambers and stimulated with S100A9. The results are presented in Fig. 2. Notably, the invasiveness of 
A

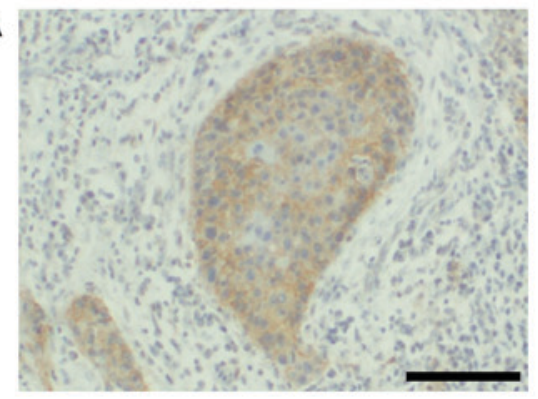

B

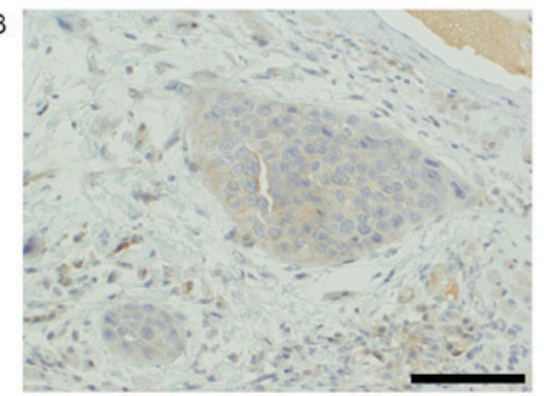

C

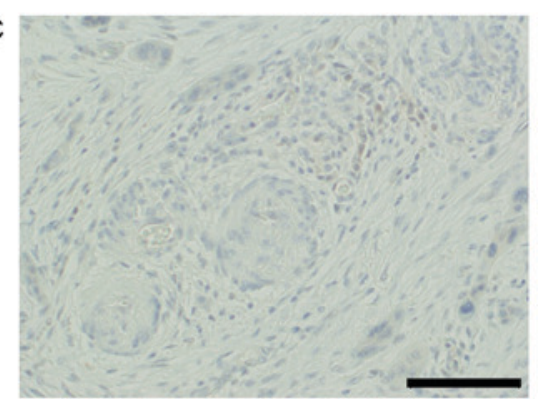

Figure 3. CD147 expression in cancer nests at the invasive tumor front. Immunohistochemical analysis of (A) CD147-positive, index $=4$ (positive area, 2; intensity, 2), (B) CD147-negative, index=2 (positive area, 2; intensity, 1) and (C) CD147-negative, index=0 (positive area, 0; intensity, 0) specimens . Magnification, x200; scale bar, $100 \mu \mathrm{m}$. CD147, cluster of differentiation 147.

Table I. Patients' characteristics and pathological findings.

\begin{tabular}{|c|c|}
\hline Variables & Patients, $\mathrm{n}$ \\
\hline Total & 41 \\
\hline \multicolumn{2}{|l|}{ Sex } \\
\hline Male & 25 \\
\hline Female & 16 \\
\hline \multicolumn{2}{|l|}{ Age (years) } \\
\hline Median & 65.8 \\
\hline Range & $33-83$ \\
\hline \multicolumn{2}{|c|}{ Tumor stage } \\
\hline $\mathrm{T} 1$ & 12 \\
\hline $\mathrm{T} 2$ & 29 \\
\hline \multicolumn{2}{|c|}{ CD147 index } \\
\hline 0 & 6 \\
\hline 1 & 7 \\
\hline 2 & 16 \\
\hline 4 & 12 \\
\hline \multicolumn{2}{|c|}{ Differentiation type } \\
\hline Poor & 4 \\
\hline Moderate & 18 \\
\hline Well & 19 \\
\hline \multicolumn{2}{|c|}{ Vessel invasion } \\
\hline Positive & 32 \\
\hline Negative & 9 \\
\hline \multicolumn{2}{|c|}{ Lymph vessel invasion } \\
\hline Positive & 28 \\
\hline Negative & 13 \\
\hline \multicolumn{2}{|c|}{ Perineural invasion } \\
\hline Positive & 13 \\
\hline Negative & 28 \\
\hline \multicolumn{2}{|c|}{ Invasion depth } \\
\hline$\geq 5 \mathrm{~mm}$ & 23 \\
\hline$<5 \mathrm{~mm}$ & 18 \\
\hline
\end{tabular}

CD147, cluster of differentiation 147.

SAS and HSC-3 cells increased when the cells were co-cultured with S100A9 $(\mathrm{P}<0.05)$. To determine whether this increased
Table II. Associations between histopathological findings and metastasis.

\begin{tabular}{|c|c|c|c|}
\hline \multirow[b]{2}{*}{ Characteristics } & \multicolumn{2}{|c|}{ Metastasis (n) } & \multirow{2}{*}{$\begin{array}{c}\text { Metastasi } \\
\text { rate }(\%)\end{array}$} \\
\hline & Positive & Negative & \\
\hline \multicolumn{4}{|l|}{ CD147 } \\
\hline Positive & 7 & 6 & 53.8 \\
\hline Negative & 4 & 24 & 14.3 \\
\hline \multicolumn{4}{|c|}{ Differentiation type } \\
\hline Moderate/poor & 9 & 13 & 40.9 \\
\hline Well & 3 & 16 & 15.8 \\
\hline \multicolumn{4}{|l|}{ Vascular invasion } \\
\hline Positive & 11 & 21 & 34.4 \\
\hline Negative & 1 & 8 & 11.1 \\
\hline \multicolumn{4}{|c|}{ Lymphovascular invasion } \\
\hline Positive & 9 & 19 & 32.1 \\
\hline Negative & 3 & 10 & 23.1 \\
\hline \multicolumn{4}{|c|}{ Perineural invasion } \\
\hline Positive & 5 & 8 & 38.5 \\
\hline Negative & 7 & 21 & 25.0 \\
\hline \multicolumn{4}{|c|}{ Invasive depth (mm) } \\
\hline$\geq 5$ & 7 & 16 & 30.4 \\
\hline$<5$ & 5 & 13 & 27.8 \\
\hline
\end{tabular}

CD147, cluster of differentiation 147.

invasiveness was mediated by the S100A9-CD147 interaction, a CD147 function-blocking antibody was added to the invasion assay. The antibody treatment reversed the increased invasiveness in SAS and HSC-3 cells $(\mathrm{P}<0.05)$, indicating that S100A9 induced tongue SCC cell invasion by stimulating CD147.

Analysis of pathological findings. Among the evaluated patients, the total rate of metastasis was $29.3 \%$ (12/41), with $16.7 \%$ $(2 / 12)$ and $34.5 \%(10 / 29)$ of patients with T1 and T2 disease exhibiting metastasis, respectively. In the clinical samples, the CD147 scores for cancer nests at the invasive tumor front were as follows: 0,$6 ; 1,7 ; 2,16$; and 4, 12 cases. Accordingly, the 12 cases scored as 4 were defined as positive, and the remaining 27 cases as negative for CD147 expression (Fig. 3). 
Table III. Univariate and multivariate analyses for risk factors related to metastasis.

\begin{tabular}{|c|c|c|c|c|c|c|}
\hline \multirow[b]{2}{*}{ Variable } & \multicolumn{3}{|c|}{ Univariate analysis } & \multicolumn{3}{|c|}{ Multivariate analysis } \\
\hline & P-value & $\mathrm{HR}$ & $95 \% \mathrm{CI}$ & P-value & HR & $95 \% \mathrm{CI}$ \\
\hline CD147 (positive vs. negative) & $0.013^{\mathrm{a}}$ & 6.720 & $1.50-30.07$ & $0.028^{\mathrm{a}}$ & 7.842 & $1.24-49.41$ \\
\hline Differentiation type (poor or moderate vs. well) & 0.087 & 3.690 & $0.83-16.51$ & 0.079 & 5.974 & $0.81-43.98$ \\
\hline Vessel invasion (positive vs. negative) & 0.202 & 4.190 & $0.46-37.94$ & 0.197 & 5.343 & $0.42-68.13$ \\
\hline Lymphatic vessel invasion (positive vs. negative) & 0.554 & 1.580 & $0.35-7.18$ & 0.632 & 0.598 & $0.07-4.89$ \\
\hline Perineural invasion (positive vs. negative) & 0.381 & 1.880 & $0.46-7.66$ & 0.442 & 0.470 & $0.07-3.23$ \\
\hline Invasive depth ( $\geq 5 \mathrm{vs} .<5 \mathrm{~mm})$ & 0.853 & 1.140 & $0.29-4.44$ & 0.705 & 0.705 & $0.11-4.32$ \\
\hline
\end{tabular}

${ }^{a} \mathrm{P}<0.05$ by univariate and multivariate logistic regression analyses. HR, hazard ratio; $\mathrm{CI}$, confidence interval; CD147, cluster of differentiation 147 .

Regarding the other histopathological findings, 18 cases were poorly differentiated, 4 cases were moderately differentiated and 19 cases were well differentiated. In addition, 32 patients exhibited vascular invasion, 28 lymphovascular invasion and 13 perineural invasion. Regarding the depth of invasion, 23 cases had a depth of $\geq 5 \mathrm{~mm}$ and 18 had a depth $<5 \mathrm{~mm}$. The patients' characteristics and pathological findings are summarized in Table I.

The following metastasis rates were associated with each pathological finding: CD147 positivity, 53.8\%; poor or moderate differentiation, $40.9 \%$; vascular invasion, $34.4 \%$; lymphovascular invasion, 32.1\%; perineural invasion, 38.5\%; and invasion depth $\geq 5 \mathrm{~mm}, 30.4 \%$. The associations between histopathological findings and metastasis are summarized in Table II.

CD147 serves as a predictor of lymph node metastasis in patients with clinical stage NO, T1-T2 SCC of the tongue. Table III shows the results of univariate and multivariate analyses of the risk factors for lymph node metastasis. The univariate analysis identified a significantly higher incidence of lymph node metastasis among $\mathrm{CD} 147$-positive cases $(\mathrm{P}=0.013)$. However, the differentiation type, vascular invasion, lymphovascular invasion, perineural invasion and invasion depth did not significantly impact the lymph node metastasis risk. A multivariate analysis confirmed that CD147 expression was an independent risk factor for lymph node metastasis in patients with clinical stage N0, T1-T2 SCC of the tongue $(\mathrm{P}=0.028)$.

\section{Discussion}

A number of rich lymphatic intercommunications associated with other regions of the mouth predispose tongue cancers to metastasize to the cervical lymph nodes (regional lymph nodes) at a relatively early stage (2); therefore, control of these lymph node metastases is an extremely important prognostic factor. Similarly, for SCC of the tongue, the presence or absence of metastasis to the cervical lymph nodes is among the most critical factors in early SCC of the tongue, particularly at stages T1 and T2 (1). Although neck dissection surgery is the most effective means of controlling cervical lymph node metastasis, it is difficult to preoperatively predict such metastases (23). This has led to controversy, as certain clinicians recommend prophylactic neck dissection, whereas others suggest avoiding unnecessary neck dissection to prevent complications $(2,3)$. Accordingly, an evaluation method that can accurately detect the presence of potential lymph node metastases is required.

Various attempts have been made to predict potential cervical lymph node metastasis, including classifications based on clinical findings such as the tumor diameter, invasiveness and thickness (20), as well as recent trials investigating biological characteristics such as specific protein expression in cancer cells $(6,24)$. Regarding the latter, associations have been reported between podoplanin, Smad interacting protein 1 and E-cadherin expression, and cervical neck lymph node metastasis in patients with early-stage SCC of the tongue $(6,24)$. Based on these previous reports, the present study investigated the association of CD147 expression in cancer nests at the deepest invasion site (a component of the invasive tumor front) with cervical lymph node metastasis in patients with early-stage SCC of the tongue. The results indicated that high CD147 expression in cancer nests at the invasive tumor front was an independent risk factor for cervical lymph node metastasis.

CD147 was originally investigated as inducer of MMPs (25). MMPs mediate the dissolution of the basement membrane and extracellular matrix, and are thus indispensable for cancer cell invasion into the vascular system and metastasis (26). The roles of MMPs were previously examined in various solid carcinomas, including head and neck cancers (27-29). Additionally, our group previously described the role of CD147 in HNSCC cell invasiveness and migration $(12,30)$. In addition, associations of CD147 expression with cervical lymph node metastasis and poor prognosis have been reported in hypopharyngeal (31) and laryngeal (7) cancers. Therefore, the potential correlation between CD147 and tumor progression, including metastasis within the head and neck region, has garnered attention.

Although specific protein expression patterns in tumors can predict lymph node metastasis and, thus, a poor prognosis, the evaluation methods remain controversial. Various methods for evaluating specific protein expression in tumor tissues have been reported $(6,24)$. However, previous studies on metastasis have reported changes and reductions in the functions of cell adhesion molecules, as well as changes in cellular properties advantageous to metastasis, along the invasive tumor front (32-35). These studies, therefore, have highlighted the usefulness of evaluating the invasive tumor front of malignant 
tumors. The importance of evaluating the expression of specific proteins at the invasive tumor front of early-stage SCC of the tongue was also previously reported (32).

According to previous studies, CD147 is expressed in invadopodia, which occur on cells at the frontline of tumor invasion, and controls the function of invadopodia by inducing MMPs (33). These findings suggest the induction of large quantities of MMP at the invasive tumor front in response to CD147 overexpression. Therefore, patients with high levels of CD147 expression in cancer nests at the invasive tumor front may be at a higher risk of metastasis due to increased invasion following the increased degradation of the basement membrane and extracellular matrix.

Notably, in the present study, the results of a cell invasion assay demonstrated that CD147 increased the invasive ability of tongue SCC cells through its interaction with S100A9. Upregulated S100A9 expression has been reported in various types of malignant tumors, including SCC of the tongue $(13,36)$. Accordingly, it is possible that, in tongue SCC cells, a high level of CD147 expression induces metastasis through increased interactions with S100A9. However, elucidation of the detailed mechanism by which CD147 promotes tumor progression is required to determine the clinical role of this protein.

When evaluating a cancer nest at the invasive tumor front, it may be necessary to identify the invasive tumor front from an excised whole-tumor specimen. Therefore, this method may not not suitable for preoperative predictions of metastatic potential in clinical NO cases, in which biopsy specimens comprise only a part of the tumor. However, this method could be used as a predictor of late metastasis, as stage T1-T2 SCC of the tongue is often followed up subsequent to primary tumor resection without neck dissection. In addition, this method typically requires time for immunostaining prior to diagnosis; however, a technique that enables immunostaining during surgery has been reported (37). If this technique is incorporated, the evaluation of CD147 expression at the invasive tumor front may be a criterion for deciding whether neck dissection should be performed during a primary lesion resection in cases of T1-T2 SCC of the tongue. Therefore, it is necessary to carefully examine the clinical usefulness of CD147.

In conclusion, it has been determined that CD147 exerts its effects on the invasiveness and metastasis of SCC of the tongue through its interactions with S100A9, and that its overexpression correlates with an increased risk of cervical lymph node metastasis. These findings support the possible use of CD147 overexpression as a marker of metastatic potential in cases of SCC of the tongue.

\section{Acknowledgements}

The authors thank Mr. Manabu Kawamura for his help in immunostaining. The present study was supported by the Japanese Society for Promotion of Science JSPS KAKENHI (grant no. 15K19706).

\section{References}

1. Haddadin KJ, Soutar DS, Oliver RJ, Webster MH, Robertson AG and MacDonald DG: Improved survival for patients with clinically T1/T2, N0 tongue tumors undergoing a prophylactic neck dissection. Head Neck 21: 517-525, 1999.
2. Huang SF, Kang CJ, Lin CY, Fan KH, Yen TC, Wang HM, Chen IH, Liao CT, Cheng AJ and Chang JT: Neck treatment of patients with early stage oral tongue cancer: Comparison between observation, supraomohyoid dissection, and extended dissection. Cancer 112: 1066-1075, 2008.

3. Lim YC, Lee JS, Koo BS, Kim SH, Kim YH and Choi EC: Treatment of contralateral N0 neck in early squamous cell carcinoma of the oral tongue: Elective neck dissection versus observation. Laryngoscope 116: 461-465, 2006.

4. Lim SC, Zhang S, Ishii G, Endoh Y, Kodama K, Miyamoto S, Hayashi R, Ebihara S, Cho JS and Ochiai A: Predictive markers for late cervical metastasis in stage I and II invasive squamous cell carcinoma of the oral tongue. Clin Cancer Res 10: 166-172, 2004.

5. Ueda G, Sunakawa H, Nakamori K, Shinya T, Tsuhako W, Tamura Y, Kosugi T, Sato N, Ogi K and Hiratsuka H: Aberrant expression of beta- and gamma-catenin is an independent prognostic marker in oral squamous cell carcinoma. Int J Oral Maxillofac Surg 35: 356-361, 2006.

6. Yuan P, Temam S, El-Naggar A, Zhou X, Liu DD, Lee JJ and Mao L: Overexpression of podoplanin in oral cancer and its association with poor clinical outcome. Cancer 107: 563-569, 2006.

7. Rosenthal EL, Shreenivas S, Peters GE, Grizzle WE, Desmond R and Gladson CL: Expression of extracellular matrix metalloprotease inducer in laryngeal squamous cell carcinoma. Laryngoscope 113: 1406-1410, 2003.

8. Hanata K, Yamaguchi N, Yoshikawa K, Mezaki Y, Miura M, Suzuki S, Senoo H and Ishikawa K: Soluble EMMPRIN (extra-cellular matrix metalloproteinase inducer) stimulates the migration of HEp-2 human laryngeal carcinoma cells, accompanied by increased MMP-2 production in fibroblasts. Arch Histol Cytol 70: 267-277, 2007

9. Sweeny L, Liu Z, Bush BD, Hartman Y, Zhou T and Rosenthal EL: CD147 and AGR2 expression promote cellular proliferation and metastasis of head and neck squamous cell carcinoma. Exp Cell Res 318: 1788-1798, 2012.

10. Xu T, Zhou M, Peng L, Kong S, Miao R, Shi Y, Sheng H and Li L: Upregulation of CD147 promotes cell invasion, epithelial-to-mesenchymal transition and activates MAPK/ERK signaling pathway in colorectal cancer. Int J Clin Exp Pathol 7: 7432-7441, 2014.

11. Hibino T, Sakaguchi M, Miyamoto S, Yamamoto M, Motoyama A, Hosoi J, Shimokata T, Ito T, Tsuboi R and Huh NH: S100A9 is a novel ligand of EMMPRIN that promotes melanoma metastasis. Cancer Res 73: 172-183, 2013.

12. Takahashi M, Suzuki S and Ishikawa K: Cyclophilin A-EMMPRIN interaction induces invasion of head and neck squamous cell carcinoma. Oncol Rep 27: 198-203, 2012.

13. Fang WY, Chen YW, Hsiao JR, Liu CS, Kuo YZ, Wang YC, Chang KC, Tsai ST, Chang MZ, Lin SH and Wu LW: Elevated S100A9 expression in tumor stroma functions as an early recurrence marker for early-stage oral cancer patients through increased tumor cell invasion, angiogenesis, macrophage recruitment and interleukin-6 production. Oncotarget 6: 28401-28424, 2015.

14. Markowitz J and Carson WE III: Review of S100A9 biology and its role in cancer. Biochim Biophys Acta 1835: 100-109, 2013.

15. Suzuki S and Ishikawa K: Combined inhibition of EMMPRIN and epidermal growth factor receptor prevents the growth and migration of head and neck squamous cell carcinoma cells. Int J Oncol 44: 912-917, 2014.

16. Erdem NF, Carlson ER, Gerard DA and Ichiki AT: Characterization of 3 oral squamous cell carcinoma cell lines with different invasion and/or metastatic potentials. J Oral Maxillofac Surg 65: 1725-1733, 2007.

17. Suzuki S, Sato M, Senoo H and Ishikawa K: Direct cell-cell interaction enhances pro-MMP-2 production and activation in co-culture of laryngeal cancer cells and fibroblasts: Involvement of EMMPRIN and MT1-MMP. Exp Cell Res 293: 259-266, 2004.

18. Bordador LC, Li X, Toole B, Chen B, Regezi J, Zardi L, Hu Y and Ramos DM: Expression of emmprin by oral squamous cell carcinoma. Int J Cancer 85: 347-352, 2000.

19. Koga K, Nabeshima K, Aoki M, Kawakami T, Hamasaki M, Toole BP, Nakayama J and Iwasaki H: Emmprin in epithelioid sarcoma: Expression in tumor cell membrane and stimulation of MMP-2 production in tumor-associated fibroblasts. Int $\mathbf{J}$ Cancer 120: 761-768, 2007.

20. Sobin LH and Wittekind CH (eds): TNM Classification of Malignant Tumours. 6th edition. John Wiley \& Sons, Hoboken, NJ, 2002

21. Asakage T, Yokose T, Mukai K, Tsugane S, Tsubono Y, Asai M and Ebihara S: Tumor thickness predicts cervical metastasis in patients with stage I/II carcinoma of the tongue. Cancer 82: 1443-1448, 1998. 
22. Koppikar P, Choi SH, Egloff AM, Cai Q, Suzuki S, Freilino M Nozawa H, Thomas SM, Gooding WE, Siegfried JM and Grandis JR: Combined inhibition of c-Src and epidermal growth factor receptor abrogates growth and invasion of head and neck squamous cell carcinoma. Clin Cancer Res 14: 4284-4291, 2008.

23. Neri S, Hashimoto H, Kii H, Watanabe H, Masutomi K, Kuwata T, Date H, Tsuboi M, Goto K, Ochiai A and Ishii G: Cancer cell invasion driven by extracellular matrix remodeling is dependent on the properties of cancer-associated fibroblasts. J Cancer Res Clin Oncol 142: 437-446, 2016.

24. Honda K, Ishiyama K, Suzuki S, Oumi E, Sato T, Kawasaki Y, Saito H and Ishikawa K: Sentinel lymph node biopsy using computed tomographic lymphography in patients with early tongue cancer. Acta Otolaryngol 135: 507-512, 2015.

25. Sakamoto K, Imanishi Y, Tomita T, Shimoda M, Kameyama K, Shibata K, Sakai N, Ozawa H, Shigetomi S, Fujii R, et al: Overexpression of SIP1 and downregulation of E-cadherin predict delayed neck metastasis in stage I/II oral tongue squamous cell carcinoma after partial glossectomy. Ann Surg Oncol 19: 612-619, 2012.

26. Guo H, Li R, Zucker S and Toole BP: EMMPRIN (CD147), an inducer of matrix metalloproteinase synthesis, also binds interstitial collagenase to the tumor cell surface. Cancer Res 60: 888-91891, 2000.

27. Nelson AR, Fingleton B, Rothenberg ML and Matrisian LM: Matrix metalloproteinases: Biologic activity and clinical implications. J Clin Oncol 18: 1135-1149, 2000.

28. Brown PD, Bloxidge RE, Stuart NS, Gatter KC and Carmichael J: Association between expression of activated 72-kilodalton gelatinase and tumor spread in non-small-cell lung carcinoma. J Nat Cancer Inst 85: 574-578, 1993

29. Davies B, Waxman J, Wasan H, Abel P, Williams G, Krausz T, Neal D, Thomas D, Hanby A and Balkwill F: Levels of Matrix Metalloproteases in bladder cancer correlate with tumor grade and invasion. Cancer Res 53: 5365-5369, 1993.
30. Wu J, Hao ZW, Zhao YX, Yang XM, Tang H, Zhang X, Song F, Sun XX, Wang B, Nan G, et al: Full-length soluble CD147 promotes MMP-2 expression and is a potential serological marker in detection of hepatocellular carcinoma. J Transl Med 12: 190 2014.

31. Suzuki S, Sato M, Senoo H and Ishikawa K: Direct cell-cell interaction enhances pro-MMP-2 production and activation in co-culture of laryngeal cancer cells and fibroblasts: Involvement of EMMPRIN and MT1-MMP. Exp Cell Res 293: 259-266, 2004.

32. Yang Q, Liu Y, Huang Y, Huang D, Li Y, Wu J and Duan M: Expression of COX-2, CD44v6 and CD147 and relationship with invasion and lymph node metastasis in hypopharyngeal squamous cell carcinoma. PLoS One 8: e71048, 2013. doi: 10.1371/journal.pone.0071048.

33. Tumuluri V, Thomas GA and Fraser IS: The relationship of proliferating cell density at the invasive tumour front with prognostic and risk factors in human oral squamous cell carcinoma. J Oral Pathol Med 33: 204-208, 2004

34. Grass GD, Bratoeva M and Toole BP: Regulation of invadopodia formation and activity by CD147. J Cell Sci 125: 777-788, 2012.

35. Bryne M, Boysen M, Alfsen CG, Abeler VM, Sudbø J, Nesland JM, Kristensen GB, Piff ko J and Bankfalvi A: The invasive front of carcinomas. The most important area for tumour prognosis? Anticancer Res 18: 4757-4764, 1998.

36. Sewell DA, Yuan CX and Robertson E: Proteomic signatures in laryngeal squamous cell carcinoma. ORL J Otorhinolaryngol Relat Spec 69: 77-84, 2007.

37. Toda H, Minamiya Y, Kagaya M, Nanjo H, Akagami Y, Saito $H$, Ito M, Konno H, Motoyama S and Ogawa J: A novel immunohistochemical staining method allows ultrarapid detection of lymph node micrometastases while conserving antibody. Acta Histochem Cytochem 44: 133-139, 2011. 